\title{
Study on Engineering Educational Accreditation Based on Outcome Based Education philosophy
}

\author{
Xia Zhu ${ }^{1, *}$, Fangqin $\mathrm{Xu}^{1}$, Zhongyun Jiang ${ }^{2}$ \\ ${ }^{1}$ Shanghai Jian Qiao University, Academic Affairs Office, 201306 Shanghai, China \\ ${ }^{2}$ Shanghai Jian Qiao University, College of Information and Technology, 201306 Shanghai, China \\ *Corresponding author. Email: 11038@gench.edu.cn
}

\begin{abstract}
Worldwide attention and recognition has gradually focused on Outcome Based Education (OBE) philosophy which was pioneered by an American scholar in 1981. Two great changes from "discipline orientated" to "expected achievement orientated" and "teacher-centered" to "student-centered" teaching ideas has occurred on the basic of OBE philosophy. It can further promote education reform which is available to solving the asymmetric problem between the graduates' abilities and the social needs. Therefore, OBE philosophy is widely used in engineering education certification (EEC). China entered formally the "Washington Agreement" in 2016. The majority of the members entered this agreement adopt the certification standard of learning achievement orientation. In this article, we will take Shanghai Jianqiao University as an example to study the implementation of EEC under the concept of OBE philosophy.
\end{abstract}

Keywords: Outcome orientation, Engineering Education Certification (EEC), Implementation of EEC

\section{INTRODUCTION}

The standards of Engineering Education Certification (EEC) were implemented after China entered the "Washington Agreement". Moreover, we have taken the contents of the agreement as the authentication criterions, i.e., learning outcomes $(\mathrm{Gu}, 2014)$. There are 1170 majors certified based on the standards of EEC as of 2018, and 460 majors have also been certified according to the No.72 document issued by the Center for Higher Education Evaluation. The research on OBE philosophy is relatively lagged in China, and is mainly concentrated in these engineering universities with high academic level. However, local universities are the important bases of developing the engineering talents' abilities to analyze and solve problems, and the backbone of the human resources in the "Made in China 2025" strategy. Therefore, it is crucial for the local universities to develop the engineering talents to promote the OBE philosophy and to introduce the standards of the EEC.

\section{EXPLORATIONS AND PRACTICES OF OBE PHILOSOPHY AT SHJU}

As a local university, the implementation of the OBE philosophy was initiated in 2016 at Shanghai Jianqiao University (SHJU). Moreover, this "student-centered", "outcome-oriented" and "sustaining improved" education concepts and attitudes are gradually seared into the hearts of the teachers and the students at SHJU after 5-year implementation of the OBE philosophy. A closed-loop continuous improvement OBE philosophy with "reverse design and forward implementation" has been initially formed at SHJU. Education reforms according to OBE philosophy at SHJU are mainly summarized as follows, (1) development of the talent cultivation objects according to country and society needs, (2) formulation of the expected "learning outcomes" based on the professional levels, i.e., graduation requirements according to talent cultivation objects, (3) establishing the matrix of the curriculum and training standards, and (4) evaluation of the learning outcomes between the professional level and the curriculum level. These education reforms are detailed in the following ( $\mathrm{Li}, 2016)$.

\subsection{Eight essential qualities of talent cultivation formulated in the light of the researches on country and society needs}

In order to achieve the essential qualities of talent cultivation, interviews and questionnaires according to the requirements of the transformation and development of local universities were conducted by more than 100 units of the school-enterprise cooperation. An inherent 
correlation among the social core values, the employers' requirements, the school motto of SHJU, and the spirit of 'Lei Feng' is built. Hence, eight core qualities, which characterize the correlation of the expectations and standards of the student development satisfied by the country, the society and the university, will be established and taken as the general outline in the talent cultivation. The eight core qualities include expression and communication, self-directed learning, professional competence, responsibility and pressure-resistance, cooperation and innovation, use of modern information technologies, service to society, and international outlook. They are completely consistent with the standards and requirements of EEC either in form or content. Finally, a specification is developed by the expected "learning outcome" at the professional level, i.e. graduation requirements, which covers the 12 general standards of EEC.

\subsection{The talent cultivation goals formulated by the expected "learning outcomes" based on the professional levels, i.e., graduation requirements}

The talent cultivation objects are also formulated according to the characteristics of the major, the industrial needs and the career prospects of the graduates beyond five years. The graduation requirements are further specified by the talent cultivation objects, which can qualify the graduates to be satisfied with the standards of EEC. In order to clearly understand the relationship, moreover, we will take Network Engineering major as a typical case as detailed in Table 1.

Table 1 A typical case of Network Engineering major

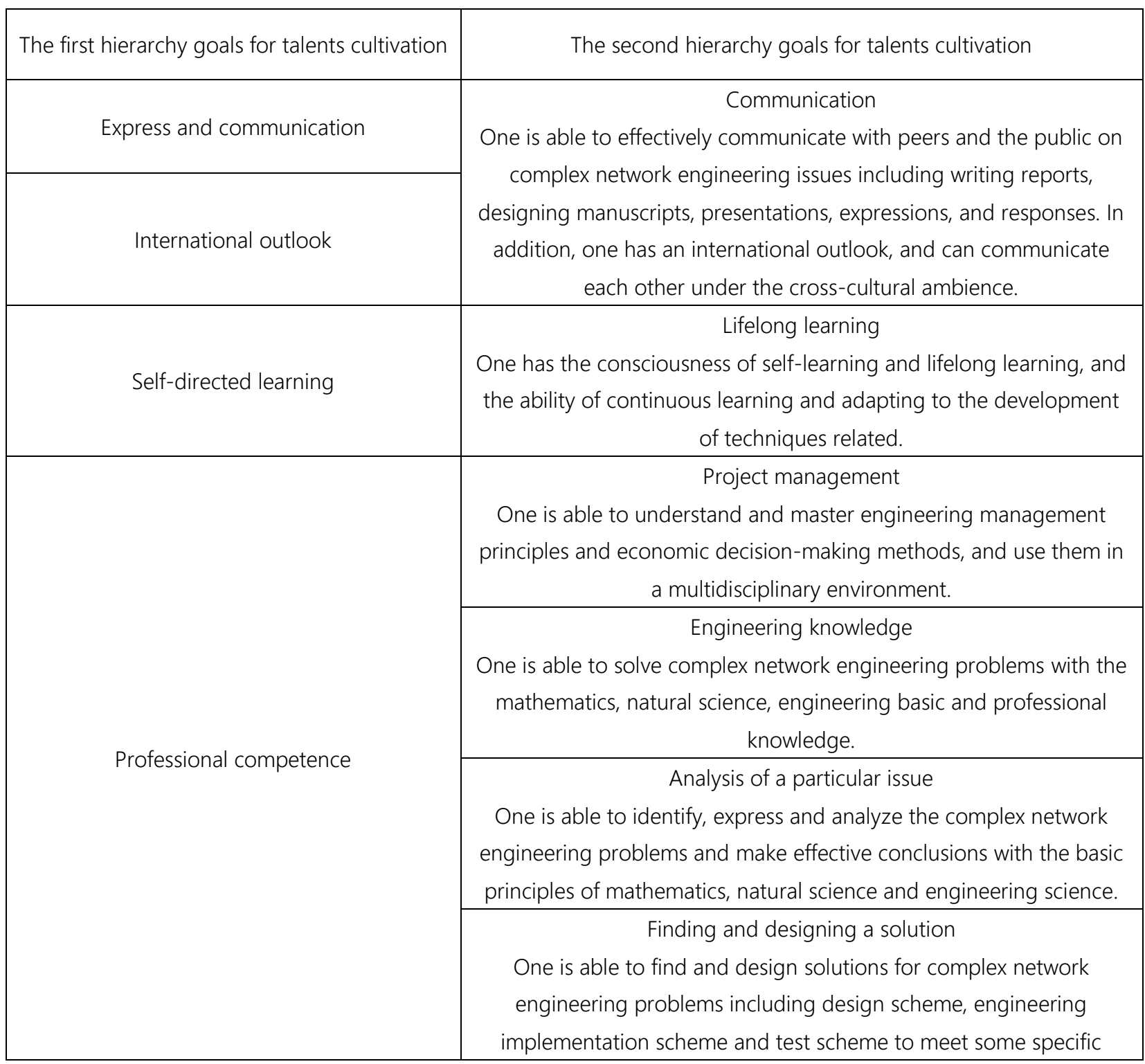




\begin{tabular}{|c|c|}
\hline & $\begin{array}{l}\text { needs, which also reflects the sense of innovation and the ideas of } \\
\text { the social, health, safety, legal, cultural and environmental factors. }\end{array}$ \\
\hline & $\begin{array}{l}\text { Research One is able to further conduct research in this field, and is } \\
\text { able to design experiments, analyze and interpret experimental data, } \\
\text { and make conclusions based on the principles and methods of } \\
\text { complex network engineering. }\end{array}$ \\
\hline responsibility and pressure-resistant & $\begin{array}{l}\text { Professional norms } \\
\text { One has the properties of humanities and social science literacy, } \\
\text { social responsibility, is able to understand and abide the professional } \\
\text { norms, and fulfill responsibilities. }\end{array}$ \\
\hline Cooperation and innovation & $\begin{array}{l}\text { Individuals and teams } \\
\text { One is able to play the role of individual, team member and leader in } \\
\text { a multidisciplinary team. }\end{array}$ \\
\hline Use of modern information techniques & $\begin{array}{l}\text { Using the modern information techniques } \\
\text { One is able to develop, choose and use appropriate technologies, } \\
\text { resources, modern engineering tools and information technology } \\
\text { tools for complex network engineering problems such as prediction, } \\
\text { simulation and the limitations. }\end{array}$ \\
\hline \multirow[t]{2}{*}{ Service to society } & $\begin{array}{l}\text { Engineering and society } \\
\text { One is able to analyze and evaluate rationally the effects of solutions } \\
\text { to the network engineering practice and complex network } \\
\text { engineering problems on society, health, safety, law and culture, and } \\
\text { understand the responsibilities. }\end{array}$ \\
\hline & $\begin{array}{c}\text { Environmental protection and the sustainable development } \\
\text { One is able to understand and evaluate properly the effects of } \\
\text { engineering practice activities on the sustainable development of } \\
\text { environment and society. }\end{array}$ \\
\hline
\end{tabular}

\subsection{Establishment of the matrix of the curriculum and training standards}

The expected "learning outcomes" at a professional level should be implemented eventually in the course (Catalano,2006). It is a crucial section for the talent cultivation to clarify the "learning outcomes" at a curriculum level. Therefore, each course should be refined and a clear goal of each course should also be lain down according to the graduation requirements. Moreover, each course goal in the graduation requirements is supported by different courses, and thus it is essential to ensure that any course has a positive effect on approaching the general goals of talent cultivation. In this case, each graduation requirement can correspond a course or several courses in curriculum. Hence, a matrix of the curriculum and the standards of the talent cultivation is established, which reflects the correlation of the graduation requirement to the courses. In addition, the contribution of each course to achieving the goal of the talent cultivation is clearly found in the matrix.

\subsection{Evaluation of the teaching input and the learning outcomes}

It is great challenge for OBE philosophy to assess the teaching input and the learning outcomes because of the involvement of any key point in OBE teaching. The course assessment is an indispensable route to balance the teaching input and the learning outcomes (Malan,2000). Engineering Education Certification based on OBE philosophy underlines the assessment of the learning outcomes reflected by the undergraduates' qualities, skills, and professional knowledge which are taught in lessons after they finish their whole courses at SHJU. Here, the final learning outcomes are implied by two different gradations. First, the graduates have the ability of professional qualities, skills and knowledge after they finish their specialty courses. Second, the graduates have the special ability of professional qualities, skills and 
knowledge beyond their major which is caught by one's personalized guidance to develop maximally his potential.

\subsubsection{Contents, methods and measures of a course assessment}

The reform of course teaching should be initiated by the teaching goals according to the standards of the OBE philosophy, and thus course teaching goals are set which are oriented by the course assessment. Moreover, the value of the undergraduates is gradually raised through the evaluation of learning. In this case, the examination ways of a course should be diversified, such as examination papers, transcripts, daily assignments, project reports, and experimental reports etc. Crucially, the achievement of a course is thoroughly evaluated by the students' academic performance, the teacher's and the students' assessments, and the valuations of the department of Educational Administration.

\subsubsection{Evaluation on the achievement according to the graduation requirements}

The valuation on the achievement according to the graduation requirements plays a vital role in the teaching quality and is also the criterion of continuous development of the teaching quality. It can be achieved through the so-called "three levels and four dimensions". Here, the "three levels" means internal evaluations by experts at SHJU, external evaluations by experts from others, and landmarks finished by students. The "four dimensions" is the valuations of the alumna, the valuations of the employers, the self-evaluations of the graduates, and the evaluations of full-time teachers. Fig. 1 shows the relationship of "three levels and four dimensions". Finally, a mechanism of continuous development on the goals of the professional talent cultivation will be formed by the implement of the "three levels and four dimensions".

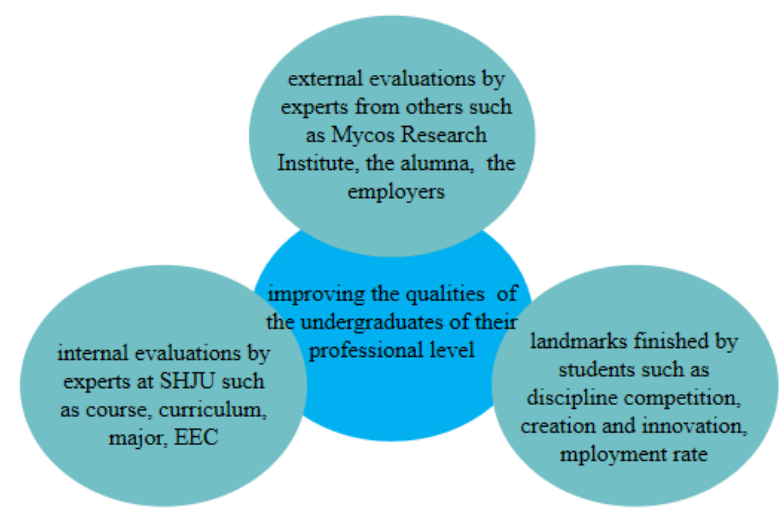

Figure 1 shows the relationship of "three levels and four dimensions".

\section{KEY ISSUES IN THE CONTINUOUS IMPLEMENTATION OF OBE PHILOSOPHY}

OBE philosophy has been carried out for more than 5 years under the concepts of top-level design promoted by the leaders of SHJU. Therefore, the general goals of the talent cultivation at school level are formed, teaching administration mechanisms are constructed, and an evaluation system of learning outcomes is gradually established in these years. More importantly, the faculties have begun to understand and accept the standards of the OBE philosophy, and even introduced them into the classroom in teaching activities. However, two issues are still needed to be addressed in the implementation of OBE philosophy.

\subsection{Deepening the reform of the "student- centered" teaching methods}

The "student-centered" teaching methods should be clearly pointed out in teaching planning according to the talent cultivation mode of OBE philosophy, which avails the development of the students' own worth and ability (Zhang,2020). A teacher prefers a heuristic teaching method in utilization of the teaching methods, and diversities of teaching methods should be advocated such as finishing a project, school-enterprise cooperation teaching, flipped classroom, and on-line and off-line teaching. Crucially, the teacher finds how to guide the students to develop the abilities of a nose for trouble, and problem-analyzing and solving, which avails a student's independence of thought. The student can enjoy the feeling of success. Finally, suitable "student-centered" teaching environment should be created in the allocation and design of teaching environment (Khalil,2018).

\subsection{Establishing a multi-level and comprehensive evaluation system}

\subsubsection{Developing a perfect evaluation system of curriculum goal achievement.}

Firstly, the teaching objects of some courses are not clear and the operability is not taken into account when setting the course objects. Hence, it is impossible to develop an easily operable evaluation method, which is not conducive to the realization of the value goal through learning evaluation. Secondly, a perfect evaluation system of curriculum goal achievement is formed. At the current stage, the domestic and international common evaluation of curriculum goal achievement is measured by adding some weighted factors including student achievement evaluation, teacher evaluation, undergraduate evaluation and college evaluation. Thirdly, the collected evaluation data and materials about curriculum goal achievement such as academic 
performance and students' evaluation are decentralized at different departments. These data and materials are not integrated, and thus a systematic and closed-loop evaluation mechanism is still absent nowadays.

\subsubsection{Developing a multi-level and multi- dimensional evaluation mechanism for the achievement of talent cultivation objectives}

The achievement of talent cultivation objectives is needed to be evaluated by teachers, students, alumni and employers when developing an evaluation mechanism (Prinsloo,2014). Firstly, in line with the design of evaluation content, each evaluation data must be deduced from the standards of OBE philosophy. Secondly, imperfection in the evaluation of teaching achievements needs to be improved such as the evaluations of graduation project (or thesis), professional competitions, EEC and employers (Volkwein,2007).

\section{RESULTS}

\subsection{The integrity and rationality of the curriculum arrangement}

According to OBE philosophy, there is a crucial point, i.e., reverse concept of the curriculum arrangement. This is in favor of arranging a more reasonable curriculum and developing a perfect curriculum system. Moreover, this underlines especially the introduction of the courses on humanities, sociology, modern information sciences and interdisciplinary general courses. Therefore, the students with solid expertise and rich professional techniques are apt to be cultivated after the introduction of the OBE philosophy at SHJU.

\subsection{The realization of the course objectives underlined as long as the reform of teaching methods}

According to OBE philosophy, the reform of curriculum teaching is motivated by the teaching objectives, and the curriculum goals should be oriented by the evaluation objectives. When setting the curriculum goals, the easy operability of learning outcome evaluation is carefully addressed, and the achievement of teaching objectives is also reflected through learning evaluation. The indicators of graduation requirements must be supported by the objectives of a course, and the content must reflect the indicators of graduation requirements supported by the course according to the reverse concept of the curriculum arrangement. A teacher finishes these results by the use of various means. Moreover, he/she should be centered in the realization of teaching objectives when he/she plans to reform his/her teaching methods.

\section{CONCLUSION}

In this paper, the evaluation concept of "studentcentered, achievement oriented and continuous improvement" is the core idea of OBE philosophy and EEC standard. The reform of student-centered teaching method is benefical to the achievement of curriculum objectives. The achievement of professional objectives is guaranteed to be finished through the achievement of curriculum objectives. Graduates have the ability to meet the needs of the industry when they graduate, and the goal of talent training is achieved on the basic of the OBE education philosophy and EEC standard.

\section{REFERENCES}

[1] Peihua Gu, Engineering education mode on the basic of OBE "learning outcome" [J].Research in Higher Education of Engineering, 2014 (1).

[2] Xiaofang Li, An empirical study on professional certification of higher engineering education, Master's thesis, Harbin University of Science and Technology,2016.

[3] Lili Zhang, Design and application of hybrid teaching mode for chemical reaction engineering under the environment of "Internet plus", Master's thesis, Northwest Minzu University 2020.

[4] George D. Catalano, Promoting peace in engineering education: modifying the ABET criteria $[\mathrm{J}]$.Science and Engineering Ethics, 2006 (2).

[5] J. Fredericks Volkwein, Lisa R. Lattuca, Betty J. Harper, Robert J. Domingo, Measuring the impact of professional accreditation on student experiences and learning outcomes [J]. Research in Higher Education, 2007 (2).

[6] S. P. T Malan, The 'new paradigm' of outcomes-based education in perspective [J].Journal of Consumer Sciences, 2000, 28: 22-28.

[7] D. J. Prinsloo, A critical evaluation of the paradigm approach in Sepedi lemmatisation - the Groot Noord-Sotho Woordeboek as a case in point [J].Lexikos, 2014 (24).

[8] Mohammed K. Khalil, Eiman M. Abdel Meguid, Ihsan A. Elkhider, Teaching of anatomical sciences: A blended learning approach [J].Clinical Anatomy, 2018 (3) 